\title{
Jorge Prelorán: las voces que aún podemos escuchar
}

\section{Acosta, Lucía}

Resumen:

En la poética del cineasta argentino Jorge Prelorán las motivaciones éticas y estéticas están estrechamente vinculadas. El presente artículo ubica su filmografía en el contexto del documental etnográfico, para destacar sus rupturas y continuidades respecto a otros realizadores nacionales e internacionales. A su vez, la circulación de la obra del director permite descubrir el potencial semántico que le confiere vigencia en la actualidad.

Por último, la dimensión ética y comprometida del trabajo fílmico de Prelorán se pone de manifiesto al señalar puntos de contacto entre sus etno biografías y los conceptos de: sujeto político, subjetivación,

Cuadernos del Centro de Estudios de Diseño y Comunicación N N 60

\begin{tabular}{|l|l}
\hline ISSN: 1668-0227 & $\begin{array}{l}\text { Lecturas y poéticas } \\
\text { del arte }\end{array}$ \\
latinoamericano: & $\begin{array}{l}\text { apropiaciones, } \\
\text { rupturas y } \\
\text { continuidades }\end{array}$ \\
Año XVII, Diciembre 2016, Buenos Aires,
\end{tabular}
Argentina | 176 páginas

descargar PDF ver índice de la publicación

Ver todos los libros de la publicación

compartir en Facebook identificación y desidentificación de Jacques Rancière.

Palabras clave:

documental etnográfico - etnobiografía - sujeto político - subjetivación - ética.

(*) Cursó la carrera de Artes (Orientación Combinadas) en la Facultad de Filosofía y Letras de la UBA. Desde 2002 trabaja en el Museo Nacional de Bellas Artes, desempeñándose en áreas dedicadas tanto a la documentación y el registro de la colección, como a la investigación.

Actualmente es asistente de investigación del Asesor Museográfico, Curadurías y Exposiciones, y Coordinador de Ediciones del MNBA, Roberto Amigo Cerisola.

"Dar voz a los que no la tienen. Lo que busco es tratar de entender cómo la gente sobrevive: mis películas son sobre sobrevivencia". 
La cita precedente pertenece a Jorge Prelorán (Rossi, 1987, p. 21). El motivo por el cual fue elegida como párrafo inaugural del presente escrito se debe a su capacidad de poner en acto una declaración de principios y una postura ética. Al definir el objetivo y el alcance de su cine, el realizador y sus imágenes toman posición. "Dar voz a los que no la tienen": punto de partida y de llegada, o principio y fin para quien supo traspasar la brecha -a menudo insalvable- entre las intenciones de los enunciados y la performatividad potencialmente inscritas en los mismos. La cita enunciada por el realizador puesta en relación con su obra, permite pensar en Jorge Prelorán como un modelo de coherencia entre sus pensamientos y sus prácticas. Al menos en un sentido profundo o vital, dado que logró plasmar en la materialidad del celuloide su gran preocupación por la humanidad, o, específicamente -y en términos de Rancière- por la parte de los que no tienen parte, convencido de la eficacia de los lenguajes audiovisuales -el cine en su caso- en la función testimonial. Si bien la actividad de Jorge Prelorán como director cinematográfico comenzó a mediados de la década del sesenta (Ocurrido en Hualfin; Trapiches caseros; Casabindo y Purmamarca, todas de 19651), recién en la década siguiente encontró un estilo que definiría todos sus films. En poco tiempo, el nombre de Jorge Prelorán fue sinónimo de "etnobiografía", diferenciándose así sus realizaciones del resto de los "documentales antropológicos", también conocidos por entonces como "documentales etnográficos".

\section{El documental etnográfico en Argentina: definición, herencia y continuidades}

Tanto para una definición como para una cronología abreviada del género en el contexto nacional, retomaré las investigaciones llevadas a cabo por Javier Campo (2012). El autor, basándose en los aportes de otros investigadores y realizadores cinematográficos, retoma como posible definición del género etnográfico, la que remite a la función de documentar diferentes grupos de personas, observando las manifestaciones culturales así como las problemáticas que enfrentan como grupo. Asimismo, Campo señala dos características que considera recurrentes a lo largo de la historia del género, la primera tiene que ver con lo que constituye el tema de registro, es decir, un otro perteneciente a una cultura diferente que se encuentra en situación de riesgo (en este sentido, el autor sigue los postulados de Bronislaw Malinovski y su práctica conocida como "etnografía de salvamento"). La segunda característica, relacionada con la praxis y definición mismas del género, se refiere a la observación y registro de contextos alejados de las grandes ciudades.

Como antecedentes del género documental etnográfico en nuestro país, Campo señala la presencia de ciertos modelos cinematográficos de registro que hacían foco en la indagación, pero acentuando, en la mayoría de los casos, el carácter exótico del grupo a documentar y, aunque menos frecuente, el paternalismo de la cultura dominante para con el grupo cultural local que devenía mero agente recesivo. En este sentido, suele datarse el inicio de la protohistoria del documental etnográfico en nuestro país en el año 1918, con El último malón, de Alcides Greca. Once años después, Gunther Pluschow, con su Vuelo en imágenes hacia mundos desconocidos, como ya lo señala el título, es sólo un ejemplo del nutrido grupo de cine de viajeros que, al igual que en este film de 1929, documentaron ese exotismo de nuestras tierras del sur, que tanto los subyugó. Un buen ejemplo de la postura paternalista mencionada más arriba, lo constituye Terre Magellaniche, film de 1933 del sacerdote Alberto Maria de Agostini para la congregación salesiana de Don Bosco, en Tierra del Fuego (un caso en el que conviven la visión misericordiosa, cargada de compasión por el indígena, con el mensaje de la salvación a través de la evangelización, esto es, destruyendo la cultura de origen2). El cambio de perspectiva lo traería la Escuela Documental de Santa Fe, casi tres décadas más tarde, con dos películas emblemáticas como Tire dié (19581968) de Fernando Birri, y Los 40 cuartos (1962) de Fernando Oliva. Ambos realizadores encontraron en el universo cinematográfico una herramienta idónea para relevar cuestiones sociales y culturales de diversos 
grupos humanos $\square$ es aquí, a mi juicio, donde se pueden establecer fuertes puntos de contacto con la poética de Jorge Prelorán, no obstante, algunos títulos de Raymundo Gleizer como La tierra quema (1964), Ceramiqueros de Traslasierra (1965) y Pictografías del Cerro Colorado (1965) son cercanos al marco temporal de producción del cine documental etnográfico de Jorge Prelorán. Si bien la diferencia fundamental entre las producciones de Gleyzer y las posteriores de Prelorán reside en la mirada marcadamente ideológica del primero, por esos años ambos cineastas trabajaron en proyectos de manera conjunta, dando como resultado dos films: Ocurrido en Hualfin (1965), con Jorge Prelorán como director y Gleyzer como montajista, y Quilino (1966), con montaje de Prelorán y dirección de Gleyzer. Luego de esas dos experiencias, los cineastas siguieron por caminos diferentes: Gleyzer, sostuvo una labor cinematográfica que acompañó su fuerte compromiso revolucionario y militante, mientras que Prelorán se pronunció en contra de cualquier ideología o propaganda, por considerarlas sinónimos de "clientelismo político".

El documental etnográfico en el mundo. Continuidades y rupturas en el universo de Prelorán

Jorge Prelorán se reconocía influenciado por el neorrealismo italiano y los documentales de los años '50, pero en más de una oportunidad, recalcó su desconocimiento de la obra de Robert Flaherty3 en el momento en que comenzó con sus primeros pasos hacia las futuras etnobiografías. No obstante, es preciso reconocer en el cine de Prelorán elementos etnográficos presentes en Flaherty, como por ejemplo, los períodos de convivencia prolongada del documentalista junto con la cultura a documentar; la contextualización del entorno de los personajes; el realismo de las técnicas a emplear así como el visionado por parte de los protagonistas del material filmado en el mismo lugar. (Piault, 2003 citado en Campo, 2012).

Asimismo, es posible señalar la relación de continuidad con las propuestas de los etnocineastas estadounidenses Timothy Ash4 y David MacDougall5, quienes le brindaron un nuevo modo de mirar. Tanto Ash como MacDougall, encontraron un referente, al menos como punto de partida, en la línea del Cinema Verité6 y el Cine directo americano7 cuyo objetivo principal era situar al espectador en el rol de observador y testigo de un fragmento de realidad. Ash, por su parte, estableció si no una ruptura, al menos una eficaz "discontinuidad" en relación con el estilo y los principios tal como los venía proponiendo el cine etnográfico hasta entonces. Con tono mordaz, denunció la necesidad urgente de un cambio en el abordaje de dichos films, a los que consideraba aburridos. Asumiéndose atrapado entre la ficción y la realidad cinematográfica, encontró una solución en el cine con función narrativa, y lo propuso como un modelo a través del cual los etnocineastas podrían aprender a contar una historia de la mejor manera posible. Dado que la historia era para Ash una forma de hacer justicia a la comunidad estudiada, remarcó la importancia de la misma, principalmente en la cuestión del protagonismo, que debía estar encarnado en los integrantes de la comunidad observada, y no en el observador y sus inquietudes.

(Brisset 1996, p. 101 citado por Priera, 1996). MacDougall, más lacónico que Ash, definió el cine etnográfico como un cine de observación. En su innovación arremetió contra la figura del antropólogo presente en el film casi como un protagonista- desde la banda de imagen y/o la de sonido (en el último caso, mediante el recurso de la narración en voz-off /over), así como a la intervención traductora o explicativa del cineasta. Consideró estas participaciones como factores de interferencia que interrumpían la recepción de los films.

Cabe aclarar en este punto que, para MacDougall, el cine etnográfico debía ser un fragmento casi inmediato, directo de la realidad (encontraba el fundamento de lo "genuino" o verdadero, en la ausencia -a mi juicio no 
reconocimiento- de las instancias de dirección, actuación, reconstrucción, dramatización). (MacDougall, 1975, pp. 109-124 citado en Ardevol Priera, 1998)8.

Jorge Prelorán, habiendo abrevado en las enseñanzas de Ash y MacDougall, tomó y descartó con sabiduría, como el apasionado y obsesivo montajista que fue, fragmentos de esa herencia que renovaría su manera filmar a partir de 1970. De MacDougall tomó la propuesta de una cámara "participativa" y "próxima" (como un medio eficaz para que los protagonistas le hablaran directamente al espectador)9, así como la cuestión de prescindir de la presencia del antropólogo y de los comentarios eruditos -algo que, a mi juicio, ya se encontraba entre sus preocupaciones. Al respecto, reconoció una primera etapa en la que sus cortos -por entonces de carácter puramente antropológicos- contaban con la asistencia de un antropólogo para la escritura del libreto, con resultados muy didácticos, pero "estériles" al mismo tiempo. Luego los datos -muy cientificistas-aportados por el antropólogo, eran leídos por un locutor. De este modo, se lograba un producto distanciado y frío, que impedía una conexión profunda con la festividad o ritual que se estaba mostrando. Con el objetivo de reducir ese efecto de distancia, se le ocurrió sustituir la voz profesional del locutor. El resultado de ese primer intento quedó plasmado en Artesanías santiagueñas, un corto de 1966, en el que se escucha al poeta santiagueño Nicanor Pereyra recitando un poema que escribió especialmente para el documental. Satisfecho con el resultado, procedió de modo similar con su corto Fiestas en Volcán Higueras, con relato y voz del puneño Anastasio Quiroga. (Prelorán 1987, pp. 24-25) Luego de repasar las declaraciones de Prelorán, me atrevería a sostener casi sin lugar a dudas que fue con Ash con quien más se identificó. Por ejemplo, declaró en varias oportunidades la difícil y doble misión del realizador etnobiográfico de ser fiel a los protagonistas, mostrando su realidad pero sin olvidarse del público, evitando su aburrimiento o incomprensión (2006, p. 63). A su vez, elaborando una suerte de propedéutica, recalcó una y otra vez, una serie de principios, directrices o consejos dirigidos al etnobiógrafo $(2006,64)$, como la importancia de llegar al lugar sin ideas preconcebidas, con tiempo y predisposición para escuchar con atención y tomar notas. Destacaba este primer acercamiento dado que de allí surgiría todo un material de gran valor testimonial -las "narrativas"- que luego el etnobiógrafo separaría según los temas (“tipos") y sus respectivas preponderancias ("pesos”). También resaltó la importancia del tiempo que se debía dedicar a detectar los temas chicos, fundamentales para configurar un contexto.

Como cierre de este apartado en el que intenté dar cuenta someramente de la concepción del realizador desde la perspectiva antropológica, me detendré en un último aspecto que considero que fue fundamental en el modus operandi del cineasta. Me refiero a la diferenciación establecida, desde los estudios antropológicos, entre dos modos de acercamiento a la cultura que se pretende estudiar/documentar/filmar: ethic approach y emic approach.

El acercamiento ético (ethic approach) es el que se establece desde afuera del contexto que es objeto de estudio u observación. En este caso se remarca notablemente la distinción entre el observador y el "otro", es decir, el observado. Dado que el observador no comparte la herencia cultural del grupo o sujeto observado, ante la inexistencia de un código que manejen ambas partes, la experiencia culmina otorgándole al grupo que se pretende "comprender" (observar/estudiar) la función de mera ilustración de teorías concebidas de antemano por parte del observador. Por el contrario, el acercamiento émico (emic approach), se propone estudiar un evento desde adentro. Este tipo de acercamiento fue el elegido por Prelorán y en esta elección residió su gran giro en el campo del documental etnográfico, dando lugar a "su" género, el que cultivó de manera prolífica por más de una década: el de las "etnobiografías"10. Para lograrlo, fue consciente de la importancia de la relación empática que debía darse con, y a través de, esos sujetos - mundos, en un doble movimiento, como de ida y vuelta 
ininterrumpido, que los iba transformando a ambos al mismo tiempo que fortalecía y profundizaba el nexo generado. En este sentido, recalcó la importancia de la personalización de la historia, como un recurso clave para lograr la empatía. De ahí surgió su necesidad de que cada película se centrase en una persona identificada con su nombre y apellidos verdaderos.

Poner en práctica el principio antropológico del acercamiento émico fue un ejercicio que el cineasta consideró como piedra basal a la hora de encarar sus proyectos. En una oportunidad, siendo entrevistado por el profesor Teshome Gabriel, dijo que la mejor forma de aprender sobre las vidas y vicisitudes de un pueblo consistía en ir hasta las fuentes [...] para conocer cómo se adaptaban las personas así como sus conquistas en los propios contextos. (Rossi, 1987, p. 122) La consigna de ir hasta las fuentes, funcionó como un precepto a lo largo y en cada uno de sus proyectos, en un sentido profundo. Mucho antes de encender la cámara o el grabador, compartía las vivencias de la comunidad -al principio como un observador silencioso que tomaba notas, más tarde, transcurrido el tiempo que posibilitaba la instancia del diálogo, como un oyente de esas historias de vida que los sujetos protagonistas elegían compartir, abriéndose a él. Y fue más lejos aún: una vez concluida la experiencia etnobiográfica, su relación con los protagonistas -que incluía a los familiares de éstos- perduró en el tiempo (en algunos casos mediante el intercambio de correspondencias, en otros -el de los que menos poseían- mediante el envío de ayuda para la subsistencia).

Itinerarios

Dado que uno de los principios más reconocidos de Jorge Prelorán fue "dar voz a los que no la tienen" (para él la finalidad misma o lo que justificaba sus realizaciones) es fundamental estar atentos a la circulación actual de su filmografía en el contexto local.

Luego del estreno oficial de casi una veintena de sus títulos en el Festival de Expresiones Folklóricas Argentinas11, llevado a cabo en el Teatro San Martín en 1969, sobrevino el silencio.

Esas películas que pretendieron dar voz a quienes no la tenían, no encontraron un canal o circuito de exhibición adecuado durante los próximos quince años12. En 1984 el cineasta regresó al país, luego de ocho años de exilio, y, el por entonces Centro Cultural General San Martín ofreció una gran retrospectiva a lo largo de quince días, con una importante afluencia de público. Según Rossi, en viajes posteriores el cineasta dictó conferencias, presidió seminarios y presentó ciclos sobre cine documental. Sin embargo, el tema de la circulación de sus películas observaba aún cierta dificultad13. Es entonces cuando surgen los primeros intentos, desde diversas disciplinas, de poner en valor de su obra. Algunos de los mentores de entonces, Guillermo Magrassi antropólogo social- y Graciela Taquini -historiadora del arte-, fueron quienes lucharon por difundir ciclos dedicados al realizador en distintos circuitos de exhibición. Desde el ámbito de la investigación, Adolfo Colombres, Mario Bommheker, Pablo Paranagua, Paraná Sendrós, Juan José Rossi, Héctor Kohen, la Fundación Universidad del Cine, Teshome Gabriel, Jorge Ruffinelli, Marcos Pérez Llahí, Ana Amado y los ya mencionados mentores (la enumeración no pretende ser exhaustiva), se avocaron al estudio de la filmografía de Prelorán -muchos de los autores, en una labor sostenida hasta la actualidad. Desde el ámbito de la realización cinematográfica, con Huellas y memoria de Jorge Prelorán, de Fermín Rivera, el realizador ya cuenta con un merecido homenaje, que incluye parte de su obra, al mismo tiempo que puede afirmarse la continuidad del legado del padre de las etnobiografías o "geografías humanas", como también le gustaba llamarlas. Huellas... se estrenó en el cine Gaumont en septiembre de 2010; un mes después se estrenó en el auditorio del Malba 
(Museo de Arte Latinoamericano de Buenos Aires - Fundación Costantini). Por otra parte y casi como en los comienzos, el público adepto a los clubes de cine pudo apreciar -y debatir sobre- la obra de Jorge Prelorán gracias a la programación ofrecida por La Rosa, un cineclub del barrio de la Recoleta. Los ciclos combinaban las proyecciones con exposiciones de fotografía14, música en vivo, conferencias a cargo de Mabel Prelorán -la mujer del realizador, compañera también en las rutas de filmación-, además de incluir la presencia de invitados especiales, como Pedro Cayo (hijo de Hermógenes, protagonista de una de las etnobiografías). En uno de estos ciclos, Mabel Prelorán tuvo a su cargo la presentación de Huellas... mencionada en el párrafo anterior. Finalmente, el universo de Prelorán, revisitado por Rivera, llegó a la televisión15.

Este año 2014, el espacio museal local dio la bienvenida al cine de Prelorán en dos oportunidades 16.

Durante el mes de abril, el Museo Casa de Ricardo Rojas exhibió los títulos más emblemáticos del realizador en el marco de su ciclo de Cine Etnográfico17. Un mes después, el Museo Nacional de Bellas Artes proyectó en forma continua el corto Iruya (1996) dentro del espacio expositivo de una muestra de americanismo18.

Valiéndose de la función documental y estética de Iruya, Roberto Amigo -curador de la exposición- incluyó el film como elemento constitutivo de su guión curatorial. El audiovisual funcionó como aglutinante de sentido, portador de la iconografía desplegada en las obras seleccionadas para la muestra. Frente a las pinturas, el espectador atento podía actualizar las escenas de Iruya visionadas con anterioridad.

La primera versión de Iruya data de 1967 y se inscribe en el marco del Programa de Relevamiento de Expresiones Folklóricas Argentinas mencionado anteriormente. Una de las características de los documentales de este período -y por la que el realizador ha recibido algunas críticas negativas- fue el carácter marcadamente didáctico. Esto se observa en la apertura del cortometraje a continuación de los títulos de crédito iniciales, desde la banda de imagen, mediante un mapa donde se señala con una flecha la ubicación geográfica de la localidad de Iruya. Sincrónicamente, desde la banda de sonido y mediante el recurso de la voz en off, Jorge Prelorán designa las coordenadas espacio-temporales y el derrotero de la localidad desde los tiempos de la conquista a la actualidad. Si bien esta elección parecería ir en contra de los principios esgrimidos por el realizador señalados en el apartado anterior, esto tiene que ver con que este documental se inscribe, como dije, dentro de sus realizaciones con fines puramente didácticos, para las cuales el horizonte de expectativa -y de recepción- del realizador lo constituyeron las instituciones educativas, antes que el público cinéfilo. De todos modos, luego de la intervención de la voz del narrador omnisciente en el prólogo, el cortometraje prescinde de este recurso, valiéndose de elementos puramente diegéticos, como el relato en voice over a cargo un habitante de Iruya.

Si bien no hemos encontrado declaraciones del director en referencia a su relación con la pintura, al recorrer su producción uno se encuentra con al menos tres títulos, en los que visita esta disciplina artística como tema: Chucalezna, Medardo Pantoja, Manos Pintadas y, dentro de lo que sería la talla de imágenes religiosas, Hermógenes Cayo.

En Artesanías santiagueñas mediante lo que denominó como "tomas íntimas", realizó una observación de cómo trabajan los artesanos. Este el primer trabajo que efectuó según un método absolutamente propio, prescindiendo de antropólogos y donde se animó a experimentar con la banda de sonido. En este cortometraje podría datarse el comienzo de su búsqueda de una narración menos artificial, catedrática y forzada, dado que su foco de 
interés no estaba puesto en la explicación de cómo se hacían las artesanías. Encontró la solución en la narración del poeta santiagueño Nicanor Pereyra.

En Medardo Pantoja, pintor, puso su atención en el quehacer minucioso del artista, pero recuperando la herencia ancestral a través de las narraciones de Don Medardo. Hermógenes Cayo, (Imaginero), además de ser su primer mediometraje, marcó un punto de inflexión en su obra, ya que, según el cineasta fue entonces donde encontró el método que mantendría en varias de sus realizaciones posteriores como Cochengo Miranda, Valle Fértil y Los hijos de Zerda. Hermógenes Cayo fue seleccionado por la crítica en 1975 entre las diez mejores realizaciones del cine argentino. (Colombres, 2005) En Chucalezna, se centró en los ejercicios pictóricos llevados a cabo por nenes de una escuela rural, en una localidad de Quebrada de Humahuaca (que da el nombre a la película).

Por el dominio alcanzado en el manejo del color, los chicos fueron reconocidos por la UNESCO en 1976.

La etnobiografía como ejercicio de subjetivación

En el presente apartado intentaré establecer algunos puntos de contacto entre la poética de Jorge Prelorán y algunas reflexiones del filósofo contemporáneo Jacques Rancière, quien encuentra en cierto tipo de cine, una posibilidad de acercamiento a cuestiones políticas. Si entendemos la política, de acuerdo con Rancière, como una cuestión de modos de subjetivación, podemos establecer fuertes conexiones con el pensamiento que Jorge Prelorán puso en acto en sus etnobiografías. En principio, Rancière, entiende la subjetivación (25) como: La producción mediante una serie de actos de una instancia y una capacidad de enunciación que no eran identificables en un campo de la experiencia dado, cuya identificación, por lo tanto, corre pareja con la nueva representación del campo de la experiencia. [...] Un modo de subjetivación no crea sujetos ex nihilo. Los crea al transformar unas identidades definidas en el orden natural del reparto de las funciones y los lugares en instancias de experiencia de un litigio.

Asimismo, considera que: Toda subjetivación es una desidentificación, el arrancamiento a la naturalidad de un lugar, la apertura de un espacio de sujeto donde cualquiera puede contarse porque es el espacio de una cuenta de los incontados, de una puesta en relación de una parte y una ausencia de parte.

La desidentificación a la que se refiere, tiene lugar en la nueva configuración del sujeto -es decir, el nuevo modo de subjetivación. Los protagonistas de las etnobiografías de Prelorán son, mediante la elección (po)ética del realizador, desidentificados, es decir, arrancados del lugar que tenían asignado por ese reparto que se instituye a sí mismo -y de manera peligrosa- como de un orden "natural": los habitantes de los confines, los que reciben en el reparto la parte de los que no tienen parte, la cuenta de los incontados. Estudiarlos como grupo étnico diferenciado (en los últimos años, un discurso encubridor y eufemista habla de "pueblos originarios"), es continuar asumiendo esa parte que les ha tocado. De este modo, la operatoria de la etnobiografía, como resultado de una experiencia -no teórica en el caso de nuestro cineasta, sino de vida, de convivencia- arranca a estos protagonistas con nombre y apellido del lugar de anonimato al que estaban confinados. Esta operatoria, entonces, consta de al menos tres movimientos: 1) acercamiento y con-vivencia 2) testimonio 3) desidentificación-identificación. La desidentificación en el sentido de Rancière es así, a mi juicio, una condición de posibilidad de la identificación de la que habla Jorge Prelorán, cuando se propone encarar "un cine que presenta los grandes problemas de la humanidad y las formas en que los individuos sin poder político responden 
a la adversidad desarrollando diferentes estrategias de control para sobrellevarla" (Rossi, 1987, p. 57). De este modo, incluso se puede avanzar un poco más, entendiendo a Prelorán con su modo de obrar como ese "operador" en quien Rancière encuentra lo que define a un sujeto político: Un sujeto político no es un grupo que 'toma conciencia' de sí mismo, se da una voz, impone su peso en la sociedad. Es un operador que une y desune las regiones, las identidades, las funciones, las capacidades existentes en la configuración de la experiencia dada, es decir en el nudo entre los repartos del orden policial19 y lo que ya está inscripto allí de igualdad, por más frágiles y fugaces que sean esas inscripciones (Rancière, s/f, p. 28).

Al respecto, cabe destacar la postura del realizador cinematográfico sobre la ideología: [...] aquellos especialmente politizados están generalmente irritados por mis películas, porque no encuentran mensajes obvios ni estridencias en ellas. Películas de propaganda de cualquier tipo me irritan. He tratado concientemente de ser respetuoso al público. No me gusta que me digan a mí qué es lo que debo pensar, de modo que tengo que ser muy cuidadoso de no imponer mis puntos de vista sobre los demás"20. Es necesario aproximarse a la experiencia de una manera pura y no movido por el deseo de obtener imágenes para defender nuestras ideas políticas21.

Poniendo el foco en la gente olvidada y ofreciéndoles un medio -artístico- para que contaran sus vivencias cotidianas, las etnobiografías de Jorge Prelorán reinscriben la esfera artística, asistiendo de este modo a una nueva configuración en la partición de la riqueza sensible y de las formas de la experiencia. Este acto de reinscripción, es una de las cualidades que Rancière encuentra en el nuevo cine político, donde no se trata de denunciar algo injusto o documentarlo, sino de hacer de la praxis fílmica una producción simbólica "justa", no en un sentido moral, sino a la medida de la experiencia.

Notas

1. Si bien en sus filmografías se incluye Venganza (1954) como su primera realización, Prelorán se refiere a este cortometraje como un mero ejercicio cinematográfico, que funcionó como disparador de su verdadera vocación pero no estableció continuidad alguna con su producción posterior (a la que da comienzo once años más tarde). Cfr. Jorge Prelorán, “Dar voz a los que no la tienen” (Rossi, 1987).

2. Véase el excelente estudio de Andrea Cuarterolo "Los antecedentes del cine político y social en la Argentina (1896-1933)" en: Lusnich, A. L. y Piedras, P. (eds.), Una historia del cine político y social en Argentina. Formas, estilos y registros (1896-1969), citado por Javier Campo, Op. Cit., p. 83.

3. Graciela Taquini sostiene que "En esencia hay una cierta relación entre Flaherty y Prelorán, ya que en ambos se expresa la armonía hombre-tierra y en la participación activa del protagonista en el film. Esa herencia la recibió a través de De Sica y Rosellini” y que "Más que una influencia determinada, Prelorán admite el hecho de que un documental tras otro fue cambiando su estilo" (Ib., p. 33). La segunda afirmación permitiría pensar en la "fase Lumière" a la que refiere Héctor Kohen (2005).

4. Timothy Asch conocido como uno de los mejores etnocineastas. Su figura, junto a las de John Marshall, Robert Gardner y Jean Rouch emblematiza lo que se ha denominado "antropología visual". 
5. David MacDougall es otro de los más importantes realizadores etnográficos y nombre fundamental en el campo de la antropología visual. Distinguido por el Real Instituto de Antropología del Reino Unido en 2013 (Lifetime Achievement Award).

6. Principales exponentes del Cinema Verité: Jean Rouch y Chris Marker.

7. Principales exponentes del Cine directo (Direct Cinema): Robert Drew; D. A. Pennebaker; los hermanos Albert y David Maysles; Frederick Wiseman.

8. Inevitablemente, las palabras de MacDougall nos reenvían a la línea fundadora del cine documental (i.e. Robert Flaherty, Dziga Vertov, Jean Vigo).

9. Cfr. Ardevol Priera, E. (1996). “Representación y cine etnográfico”, Quaderns de l'ICA, n 10, p. 12.

10. En 1968, Jorge Preloran fue invitado al Primer Coloquio Internacional de Cine Etnográfico llevado a cabo en la Universidad de California, para proyectar sus documentales.

Según declaró, recién entonces se enteró de la existencia del género denominado "cine etnográfico" y, en consecuencia, de que sus películas habían sido incluidas dentro de ese género. Tiempo después, alguien le sugirió que algunas de sus realizaciones podrían denominarse "etnobiografias" y él, sintiéndose cómodo con la denominación, la adoptó desde entonces. (Rossi 1987, p. 91) 11. Los films presentados fueron realizados gracias al subsidio del Fondo Nacional de las Artes (FNA) en convenio con la Universidad de Tucumán durante la gestión del Profesor Augusto Raúl Cortázar , coordinador del proyecto de Relevamiento de Expresiones Folklóricas Argentinas. Títulos que integraron dicho programa e incluidos actualmente en la base de datos del FNA: Casabindo; Trapiches caseros y Feria de Simoca (los tres de 1965); Quilino (1966); Hermógenes Cayo (1966/67); Iruya y La feria de Yavi (ambos de 1967); La Iglesia de Yavi (s/f) [en el Archivo Prelorán se consigna la el año 1979, pero debe haber existido alguna versión anterior a 1969]; Chucalezna; Medardo Pantoja y Señalada en Juella (los tres de 1968); Damacio Caitruz (Araucanos de Ruca Choroy), (1970) [si bien el FNA consigna 1970 como año de realización, señalo, como en el caso de La Iglesia de Yavi, la posibilidad de existencia de una versión anterior a 1969].

12. A pesar de la trascendencia que el director y sus realizaciones lograban a nivel internacional: en 1978, por ejemplo, fue invitado a participar en el Festival 'Margaret Mead' de Cine Antropológico, de Nueva York.

13. Si bien su trascendencia a nivel internacional iba en notorio aumento (entre varias distinciones, fue candidato a un premio Oscar en 1981, así como seleccionado para concursar en el Festival de Biarritz en 1983), no ocurría lo mismo a nivel local. Hacia 1987, sus etnobiografías seguían siendo conocidos sólo por la gente "del medio" [cinematográfico]. Cfr. “Jorge Prelorán. 'Regresé para filmar hasta el hartazgo', en: Clarín, Buenos Aires, miércoles 9 de septiembre de 1987 [ s/n - página inicial del Suplemento de espectáculos].

14. Exposición fotográfica Filmando a Prelorán. Diario de viaje, de Rivera (Director de Huellas y Memoria...) y Emiliano Penelas (Director de Fotografía del mismo film).

15. Los canales Encuentro e INCA tv incluyeron el film de Rivera en su programación. 
16. Con anterioridad, varios museos del exterior lo invitaron incluyendo sus realizaciones en su programación: el Museo de Antropología de México; El Museo de Arte Moderno de Nueva York (donde estrenó Los hijos de Zerda), el Musée de l'Homme de París, entre otros.

17. El ciclo, de frecuencia semanal, incluyó los siguientes títulos: Hermógenes Cayo (1967); Casabindo (1965); Iruya (1967); Quilino (1968); La Feria de Yavi (1967); Señalada en Juella (1968) y Damacio Caitruz (Araucano de Rucachoroy) (1970).

18. “La Hora Americana 1910-1950”, Museo Nacional de Bellas Artes, Buenos Aires, junioagosto de 2014.

19. El orden policial es en el pensamiento de Rancière lo que habitualmente -y fuera de su pensamiento- se ha naturalizado como significado del término "política". Para una comprensión profunda de la acepción, cf. Rancière, Op. Cit.

20. Gutiérrez, G. “Cine político y popular de una Argentina Mestiza” en Rossi, Op. Cit. P. 57.

21. Extraído de la entrevista realizada por el profesor Teshome Gabriel (Universidad de California) a Prelorán (Rossi, 1987).

Filmografía de Jorge Prelorán

1954: Venganza 1956: A las tres 1957: The Unvictorious One 1960: Delirium Tremens Reserve in Action 1961: Death, don't be proud 1962: El llanero colombiano El gaucho argentino, hoy El gaucho de las pampas El gaucho salteño El jinete correntino 1963: La patagonia argentina Costas patagónicas Costumbres neuquinas 1964:

Potencial dinámico de la República Argentina Anfibios, reproducción y desarrollo El estudio de las plantas 1965:

La biología experimental Trabajos paleontológicos en la Argentina Reptiles fósiles triásicos de la Argentina Dinosaurios 1966: Claudia Purmamarca Trapiches caseros Las rondas de Valle Fértil Máximo Rojas, monturero criollo Feria en Simoca Ocurrido en Hualfín 1967: Casabindo El Tinkunaku Salta y su fiesta grande Viernes Santo en Yavi Quilino 1968: Un tejedor de Tilcara Artesanías santiagueñas Medardo Pantoja, pintor Iruya 1969: La feria de Yavi Señalada en Huella Fiestas en Volcán Higueras Hermógenes Cayo, (Imaginero) Chucalezna 1971: El grano dorado Remate en estancia Manos pintadas Araucanos de Ruca Choroy 1972: Valle fértil El picaflor de cola larga 1973: Los Onas, vida y muerte en Tierra del Fuego 1974: Cochengo Miranda 1975: Los Guaraos 1977: La iglesia de Yavi 1978: La máquina Los hijos de Zerda 1979: Luther Metke at 94 1980: Castelao (Biografía de un ilustre gallego) Héctor Di Maurdo, titiritero 1983: Mi tía Nora

Bibliografía consultada

Aguilar, G. y España, . (2005). Cine argentino. Modernidad y vanguardias 1957-1983. Buenos Aires: Fondo Nacional de las Artes.

Ardèvol Piera, E. y Pérez Tolón, L. (1965). Imagen y cultura. Perspectivas del cine etnográfico. Granada: Diputación Provincial de Granada y Biblioteca de Etnología.

Ardèvol Piera, E. (1996). “Representación y cine etnográfico”, Quaderns de l'ICA, n 10. Disponible en: http://cv.uoc.edu/ grc0_000199_web/pagina_personal/eardevol_online_pub.htm (1998) "Por una 
antropología de la mirada: etnografía, representación y construcción de datos audiovisuales" en Martínez Sanalova Sánchez, E. (sel) Lecturas de cine documental y etnográfico. Disponible en: www.uhu.es Bianco, A. Entrevista a Fermín Rivera. Disponible en: www.pagina12.com.ar/diario/suplementos/espectaculos/5-194402010-09-30.html replicado en cinealsur.blogspot.com.ar Campo, J. (2012). Cine documental argentino. Entre el arte, la cultura y la política. Buenos Aires: Imago Mundi.

Colombres, A. (Ed.) (2005). Cine, antropología y colonialismo. Buenos Aires: Ediciones del Sol.

Flaherty, R. "La función del documental”, en Columbres, A. (ed.), Cine, antropología y colonialismo. Buenos Aires: Ediciones del Sol.

Gutiérrez, G. (1976). “Cine político y popular de una Argentina mestiza”, en Rossi, J. J.

(comp.) (1987). El cine documental etnobiográfico de Jorge Prelorán. Buenos Aires: Ediciones Búsqueda.

Kohen, H. "La aventura del homo faber. El cine de Jorge Prelorán”. En Aguilar, G. y España, C. (2005). Cine argentino. Modernidad y vanguardias 1957-1983. Buenos Aires: Fondo Nacional de las Artes.

Paranaguá, P. A. ed. (2003). Cine documental en América Latina. Buenos Aires: Cátedra.

Piault, M. H. (2002). Antropología y cine. Madrid: Cátedra.

Prelorán, J. "Conceptos éticos y estéticos en cine etnobiográfico" y “Dar voz a los que no la tienen” en: Rossi, J. J. (comp.) (1987). El cine documental etnobiográfico de Jorge Prelorán. Buenos Aires: Ediciones Búsqueda. . (2006) El cine etnobiográfico. Buenos Aires: Editorial Catálogos Universidad del Cine [con una entrevista de Paraná Sendrós a modo de introducción].

Rancière, J. El desacuerdo. Política y filosofía. Buenos Aires: Ediciones Nueva Visión, s/d [La mésentente. Politique et philodophie, París: Éditions Galilée].

Rossi, J. J. (comp.) (1987). El cine documental etnobiográfico de Jorge Prelorán. Buenos Aires: Ediciones Búsqueda.

Taquini, G. "Los documentales de Jorge Prelorán: un cine antropomórfico" en Rossi, J. J. (comp.) (1987). El cine documental etnobiográfico de Jorge Prelorán. Buenos Aires: Ediciones Búsqueda.

Teshome, G. Entrevista a Jorge Prelorán publicada en 1987 por la Universidad de California, reproducida por Rossi, J. J. (comp.) (1987). El cine documental etnobiográfico de Jorge Prelorán. Buenos Aires: Ediciones Búsqueda y por la Revista Chilena de Antropología Visual, $n^{\circ} 3$, Santiago de Chile, 2003. Disponible en www.rchav.cl/entrevistas.htm Recursos en línea

nidodecaranchos.blogspot.com.ar/2012/03/el-cine-etnobiografico-de-jorge.html www.jorgepreloran.blogspot.com.ar www.ucine.edu.ar/ebooks/PRELORAN.pdf 
In the poetics of the argentine filmmaker Jorge Prelorán, ethical and aesthetic motivations are closely linked. This article locates his films in the context of ethnographic documentary to highlight their ruptures and continuities over other national and international filmmakers. At the same time, the traffic of the work of the director allows the discovery of the semantic potential which gives effect today. Finally, ethical and committed dimension of the film work of Prelorán arises when addressing points of contact between their ethno biographies and the concepts of political subject, subjectivity, identification and disidentification of Jacques Rancière.

Key words:

etnographic documentary - ethno biography - public subject - subjectivity - ethics.

\section{Resumo:}

O artigo revisa a figura do cineasta Jorge Prelorán, a partir das motivações éticas e estéticas que definiram sua poética. Depois de introduzir sua filmografia, se expõe a situação do documental etnográfico no âmbito nacional e internacional, considerando continuidades e rupturas. Logo, se esboça uma cartografia abreviada da circulação da obra do cineasta, observando a produtividade que hoje lhe dá vigência. Para terminar, se mencionam alguns pontos de contato entre as etnobiografias de Jorge Prelorán e o pensamento de Jacques Rancière, especificamente a partir das noções de sujeito político, subjetivação e identificação dês-identificação.

Palavras chave:

documental etnográfico - etnobiografia - sujeito político - subjetivação - ética.

Jorge Prelorán: las voces que aún podemos escuchar fue publicado de la página 73 a página86 en Cuadernos del Centro de Estudios de Diseño y Comunicación № 60 